\title{
"We Are Watching": The effectiveness of implementing novel anti-smoking signage on hospital property
}

\author{
Lorna Sampson*1, Navjot Rai ${ }^{2}$, Audra Vair ${ }^{1}$, Anoush Yaminifar ${ }^{3}$, John Abrahamson ${ }^{4}$ \\ ${ }^{1}$ Office of Research, Toronto East General Hospital, Toronto, ON, Canada \\ ${ }^{2}$ Faculty of Medicine, University of Toronto, Toronto, ON, Canada \\ ${ }^{3}$ Toronto East General Hospital, Toronto, ON, Canada \\ ${ }^{4}$ Department of Medicine, Toronto East General Hospital, Toronto, ON, Canada
}

Received: September 10, 2015

Accepted: December 30, 2015 Online Published: January 11, 2016

DOI: $10.5430 /$ jha.v5n2p69

URL: http://dx.doi.org/10.5430/jha.v5n2p69

\begin{abstract}
Objective: Poor adherence to smoke-free policies on hospital property is an ongoing challenge. This study introduced novel anti-smoking signage onto hospital property with the aim of evaluating its effectiveness on reducing the incidence of smoking in designated areas.

Methods: This prospective ecological study used cigarette butt count as a proxy to measure smoking prevalence at a single hospital's three exit sites between October-December 2013. A pre-analysis of cigarette butt count at each site was conducted and the site with the highest count was selected for intervention; the two remaining sites were controls. The intervention signs featured a pair of stern male eyes with a forward gaze with "Don't Smoke" written in black font and "We Are Watching" in red font below. Pre- and post-intervention cigarette butt counts were collected over 18 days and 14 days respectively. Climate was included in the analysis.

Results: The number of cigarette butts decreased at the intervention site across 11 of the 14 post- intervention monitored days (29.8\% decrease). Cigarette butt counts increased across both control sites (32.9\% and 58.8\%). One-way ANOVA revealed a significant interaction $(p=.000)$ between location and pre-/post-intervention periods. A two-way ANOVA evaluating location, intervention period, and climate temperature change ( \pm 10 degrees Celsius) revealed statistical significance $(p<.05)$. Interaction between location and climate was not significant.

Conclusions: This study demonstrated a decrease in cigarette butts at the hospital exit where the "watching eyes" signs were implemented. Simple, low-cost anti-smoking interventions such as this may assist in creating healthier, smoke-free environments on hospital properties.
\end{abstract}

Key Words: Smoking cessation, Hospital policy, Anti-smoking signage, Tobacco control

\section{INTRODUCTION}

Smoking remains the number one cause of preventable death. ${ }^{[1]}$ Smoking is the leading cause of lung cancer and chronic obstructive pulmonary disease and is a risk factor for other cancers, respiratory, and cardiovascular diseases. ${ }^{[1,2]}$ Considering the health risks and burden on the healthcare

\footnotetext{
*Correspondence: Lorna Sampson; Email: lornasampsonriden@ rcsi.ie; Address: Office of Research, Toronto East General Hospital, Toronto, ON, Canada.
} 
system, efforts to reduce smoking have to be enforced and improved upon to help reduce the societal burden of smoking.

Smoke-free policies on hospital properties are in place to reduce tobacco smoke exposure to employees, patients and visitors and to deliver an important public health message about the harmful effects of smoking. ${ }^{[3-6]}$ Hospitals are not only primary sites of healthcare provision, but also a source of employment and community leadership and have a great responsibility to protect people from smoke exposure. ${ }^{\text {[7] }} \mathrm{Sev}$ eral studies have examined the effect of smoke-free policies on hospital property and reveal that non-compliance continues to be a challenge, as evidenced by discarded cigarette butts around common exits and hospital grounds. ${ }^{[5,7-9]}$ Two Canadian studies suggest that non-compliance with hospital anti-smoking policies is due to a complex interplay of addiction, safety, disrespect for property and the treatment gap between the availability of tobacco dependence treatment programs and those who require them. ${ }^{[6,10]}$ While there is a paucity of data in this area, it is clear that additional interventions may be required to impact the prevalence of smoking on hospital property and ensure that all visitors, patients, and employees are maintaining the smoke-free environment.

A new type of signage has shown evidence of modification of social behaviour. The "watching eyes effect" as studied by Nettle et al. revealed that the use of signage containing the simple images of watching eyes encouraged pro-social behaviour. ${ }^{[11]}$ Specifically, the use of the watching eyes has revealed individuals are more likely to give money to people in need, pay for drinks, donate to charity, recycle appropriately, and less likely to leave litter on tables or steal bicycles. ${ }^{[12]}$ These authors suggest the effect of being observed encourages people to act in ways that are more socially desirable. It remains to be investigated if such signage could impact other social behaviours, such as smoking behaviour. No studies to date have evaluated the effect of such signage on adherence to anti-smoking policies.

This study examined the effect of the watching eyes signage on smoking prevalence on the property of a single community-based teaching hospital in Toronto, Canada. We aimed to evaluate the usefulness of an alternative type of antismoking signage and a means to reduce smoking incidence on hospital property and exposure of secondhand smoke to visitors, patients and staff.

\section{MethodS}

\subsection{Study setting}

Toronto East General Hospital (TEGH) serves a population that is less wealthy and less educated than Toronto aver- ages. ${ }^{[13]}$ Annually, TEGH provides care for nearly 20,000 inpatients, has more than 60,000 emergency visits, and 215,000 outpatient visits. ${ }^{[13]}$ TEGH has three primary sites of entry and exit to the building that for study purposes are named the Front, Back and Emergency Exits. All three sites have multiple "no smoking" signs and painted walkways indicating they are smoke-free zones. The pre-existing "no smoking" signs are Toronto Municipal Code Chapter 709 Bylaw signs which indicate "No Smoking Within 9 metres of Building Entrance or Exit" and include the recognizable image of a black cigarette surrounded by a red circle with a line crossed through it.

\subsection{Experimental intervention}

Cigarette butt count was used as a proxy to measure smoking prevalence on hospital property. This was used to quantify differences across the three selected sites pre- and post-experimental intervention. A pre-analysis of the total cigarette butts at each site revealed the Back Exit as the site with the highest prevalence of smoking activity. The Back Exit was selected as the intervention site and the other two (Front and Emergency) served as controls. Durable intervention signs measuring $2 \mathrm{~m} \times 3 \mathrm{~m}$ were installed at the Back Exit; no changes were made to the pre-existing municipal bylaw signage at the control sites.

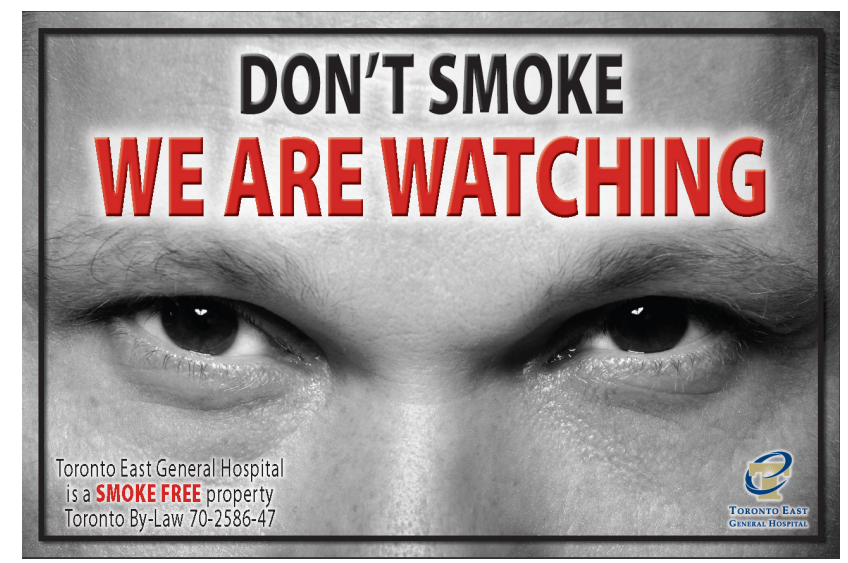

Figure 1. Novel anti-smoking signage (study intervention)

The intervention signs (see Figure 1) were positioned on walls approximately $2.5 \mathrm{~m}$ from the ground to provide maximum visibility. Four signs were posted at the Back Exit with two additional smaller signs $(30 \mathrm{~cm} \times 35 \mathrm{~cm})$ posted in windows along the Back Exit. The signs featured a black and white image of a pair of male eyes with a direct forward gaze. The signs included the words "Don't Smoke" in black font and "We Are Watching" in red font. 


\subsection{Evaluation}

This study used a simple and reproducible quantitative approach to evaluate the effectiveness of the "watching eyes" signs. Cigarette butts were collected and counted on each assessment date by maintenance support staff at the three sites. The counts occurred several times over the course of a single day and staff did not interrupt or approach any smokers at each of the monitored sites. Total counts were reported daily and re-counted by research staff. Pre-site analysis was conducted across 18 days from September-October 2013. The signage was installed on October 202013 at the Back Exit and post-intervention measures were taken over 14 days from October-December 2013. To account for the effect of weather, the average daily temperature on each day was recorded using accuweather. com.

\subsection{Analysis}

Cigarette butts were counted during the pre- and postintervention periods. Locations, pre- and post-intervention period and average daily temperature were included in the final analysis. Repeated-measures analysis of variance (ANOVA) was used to further analyze these data.

\subsection{Ethics}

Use of the watching eyes signs was conducted as part of a quality improvement project. No patients, visitors or staff were approached nor identified. The TEGH Research Ethics Board approved this study.

\section{RESUlts}

The number of cigarette butts decreased at the intervention site on 11 of the 14 post-intervention monitored days with a $29.8 \%$ average decrease in butt count (see Table 1). This is a marked contrast to the pre-intervention analysis demonstrating the Back Exit had higher cigarette butt counts on 13 out of the 18 monitored days. Cigarette butt counts were seen to increase across both the Front and the Emergency Exits following the intervention at $32.9 \%$ and $58.8 \%$ respectively. The three sites saw was a $5.7 \%$ average increase in cigarette butts across the intervention period. Table 1 reports the summed total averages pre- and post-intervention across the three study sites and the percent change in the cigarette butt count.

Table 1. Average total cigarette butt count and calculated percent change

\begin{tabular}{llll}
\hline Location & Pre-Intervention & Post-Intervention & Percent Change \\
\hline Front & 149 & 198 & $32.9 \%$ \\
Back & 171 & 120 & $-29.8 \%$ \\
Emergency & 119 & 189 & $58.8 \%$ \\
Total & 439 & 508 & $5.7 \%$ \\
\hline
\end{tabular}

Published by Sciedu Press
A one-way ANOVA was calculated for location (Back, Front and Emergency Exits) and period (pre- and post-intervention) and was found to differ statistically $(p=.000)$. When daily climate (mean daily temperature) was added to the model, a two-way ANOVA demonstrated that the interaction between location and period retained significant variation $(p<.05)$. Interaction between location and temperature not found to be significant.

\section{Discussion}

This modest prospective ecological study evaluated the usefulness of an alternative approach to anti-smoking signage as a means to reduce smoking incidence on hospital property and exposure of second-hand smoke to visitors, patients and workers. Despite current bylaw signage and hospital policies, the non-compliance reported in this study is in line with current literature. ${ }^{[6-10,14]}$

The tendency for people to change their behaviour when they are being watched, or The Hawthorn Effect, has been successfully applied to hospital hand hygiene campaigns. ${ }^{[15-17]}$ The decrease in cigarette butt count at the intervention site suggests the watching eyes effect might have effected patient, visitor and staff compliance with hospital smoke-free policy. However, the reciprocal increase in cigarette butt count across the other two sites frequented by smokers suggests there was likely a displacement of smokers and a noncompliance with hospital policy. While neither the long-term impact of the watching eyes signage nor an installation of the signs across all exit sites have been investigated, there is evidence that this inexpensive and simple intervention could be used concomitantly with measures to reduce smoking.

There are several limitations to this study. The study duration was relatively short, which may have influenced the findings. It is possible that the butt collection and counts throughout the study period could have influenced smoker behaviour. However, the butt collection was done by custodial support staff as part of routine hospital property garbage collection and the researchers counted the butts from the collected garbage offsite. Given the brief nature of this study, the impact of the signage on different populations could not be appreciated. Specifically, it is unknown whether the signs might have had a negative impact on patients with altered mental health status, since "watching eyes" could be interpreted as threatening to such patients. Finally, this study could not discern the TEGH smoking population nor differentiate between the groups of smokers on hospital property and thus it is unknown if the signs specifically impacted staff, patient or visitor compliance with hospital policies. Future research, which captures smoker demographic information, qualitative data on smoker response to novel interventions 
and a longer study period across several institutions, is warranted.

\section{Conclusions}

Poor compliance with anti-smoking policies on hospital properties presents an ongoing health challenge worthy of creative intervention. This study demonstrated a decrease in cigarette butts at the hospital exit where the "watching eyes" signs were implemented. Simple, low-cost anti-smoking interventions such as these may assist in creating healthier, smoke-free environments on hospital properties.

\section{What this paper adds}

- This study presents an evaluation a creative, low-cost intervention to ameliorate the poor adherence to antismoking policies on hospital property.

- This study reports a decrease in cigarette butts (proxy for smoking prevalence) at the hospital exit where the "watching eyes" intervention signs were implemented.
- This intervention could be used concomitantly with additional measures to reduce smoking in designated non-smoking areas, thereby reducing tobacco exposure to patients, staff and visitors.

\section{Contribution statement}

LS drafted the manuscript, supervised the project and integrated essential feedback from the other authors. JA and AV were responsible for the development of the proposal and project supervision. NR and AY were involved in the collection, analysis and interpretation of the data. All of the authors provided feedback on the revisions to the manuscript and approved of the final version submitted for publication.

\section{Funding sources}

This project was supported by a research grant from the TEGH Foundation, Community-Based Research Fund.

\section{CONFLiCTS OF INTEREST Disclosure}

The authors declare they have no conflict.

\section{REFERENCES}

[1] Makomaski Illing EM, Kaiserman MJ. Mortality attributable to tobacco use in Canada and its regions, 1998. Canadian Journal of Public Health Revue Canadienne De Santé Publique. 2004; 95(1): 38-44. PMid: 14768740.

[2] Canada. Chronic Disease Risk Factor Analysis. 2013. Available from: http://www.phac-aspc.gc.ca/cd-mc/atlas/in dex-eng.php

[3] Fox SD, Shovein J. Achieving smoke-free hospitals. Tips for administrators. Hospital topics. 1993; 71(3): 29-32. PMid: 10129078 http://dx.doi.org/10.1080/00185868.1993.9950556

[4] Kunyk D, Els C, Predy G, et al. Development and introduction of a comprehensive tobacco control policy in a Canadian regional health authority. Preventing chronic disease. 2007; 4(2): A30. PMid: 17362621.

[5] Parle D, Parker S, Steeves D. Making Canadian healthcare facilities $100 \%$ smoke-free: a national trend emerges. Healthcare quarterly. 2005; 8(4): 53-7, 2.

[6] Schultz AS, Finegan B, Nykiforuk CI, et al. A qualitative investigation of smoke-free policies on hospital property. CMAJ. 2011; 183(18): E1334-44. PMid: 22042991. http://dx.doi.org/10. $1503 /$ cmaj. 110235

[7] Sheffer C, Stitzer M, Wheeler JG. Smoke-free medical facility campus legislation: support, resistance, difficulties and cost. International journal of environmental research and public health. 2009; 6(1): 246-58. PMid: 19440281. http://dx.doi.org/10.3390/ijerp h6010246

[8] Ratschen E, Britton J, McNeill A. Smoke-free hospitals - the English experience: results from a survey, interviews, and site visits. BMC health services research. 2008; 8: 41. PMid: 18282278. http://dx.doi.org/10.1186/1472-6963-8-41

[9] Shipley M, Allcock R. Achieving a smoke-free hospital: reported enforcement of smoke-free regulations by NHS health care staff
Journal of public health. 2008; 30(1): 2-7. PMid: 18292178. http: //dx.doi.org/10.1093/pubmed/fdn004

[10] Reid RD, Mullen KA, D' Angelo MES, et al. Smoking cessation for hospitalized smokers: an evaluation of the "Ottawa Model". Nicotine $\&$ tobacco research: official journal of the Society for Research on Nicotine and Tobacco. 2010; 12(1): 11-8. PMid: 19903737. http://dx.doi.org/10.1093/ntr/ntp165

[11] Nettle D, Nott K, Bateson M. 'Cycle thieves, we are watching you': impact of a simple signage intervention against bicycle theft. PloS one. 2012; 7(12): e51738. PMid: 23251615. http://dx.doi.org /10.1371/journal. pone.0051738

[12] Bateson M, Callow L, Holmes JR, et al. Do images of "watching eyes' induce behaviour that is more pro-social or more normative? A field experiment on littering. PloS one. 2013; 8(12): e82055. PMid: 24339990. http://dx.doi.org/10.1371/journal.pon e. 0082055

[13] Our Community, Our Services: A Profile of the TEGH Community and Patients. Toronto: Toronto East General Hospital; 2011.

[14] Lawn S. Habit or addiction: the critical tension in deciding who should enforce hospital smoke-free policies. CMAJ. 2011; 183(18): 2085-6. PMid: 22042997. http://dx.doi.org/10.1503/cmaj . 111579

[15] WHO launches global patient safety challenge; issues guidelines on hand hygiene in health care. Indian journal of medical sciences. 2005; 59(10): 461-3. PMid: 16312059.

[16] Haas JP, Larson EL. Measurement of compliance with hand hygiene. The Journal of hospital infection. 2007; 66(1): 6-14. PMid: 17276546. http://dx.doi.org/10.1016/j.jhin.2006.11.013

[17] Srigley JA, Furness CD, Baker GR, et al. Quantification of the Hawthorne effect in hand hygiene compliance monitoring using an electronic monitoring system: a retrospective cohort study. BMJ quality \& safety. 2014; 23(12): 974-80. PMid: 25002555. http: //dx.doi.org/10.1136/bmjqs-2014-003080 